\title{
Multiple Primary Pathologies in a Patient with Primary Hyperparathyroidism
}

\author{
Ryner Jose DC. Carrillo ${ }^{1,2}$ and Precious Eunice R. Grullo² \\ ${ }^{1}$ Department of Anatomy, College of Medicine and Philippine General Hospital, University of the Philippines Manila \\ ${ }^{2}$ Department of Otorhinolaryngology, College of Medicine and Philippine General Hospital, University of the Philippines Manila
}

\begin{abstract}
Co-existence of multiple pathologies affecting a patient poses a challenge in the diagnosis and management. A rare combination of early tongue cancer, maxillary fungal rhinosinusitis, calcified thyroid nodule and primary hyperparathyroidism in a 70-yearold female is described. The evidences used for disease probabilities based on diagnostic results and effectivess of treatment modalities are presented. The decision-making process to come up with an individualized management is discussed.
\end{abstract}

Key Words: parathyroid adenoma, fungal rhinosinusitis, maxillary calcification, calcified thyroid nodule, tongue cancer

\section{Introduction}

Management of head and neck neoplasms depends on probabilistic thresholds provided by current guidelines and literature. The types of disease can be highly variable, and the choice between observation and invasive treatment is usually influenced by disease type probability and effectiveness of treatment. An early tongue cancer has $23 \%$ chance of occult neck node metastasis; elective neck dissection on early tongue cancer decreases node-related mortality and increases 5 year disease - specific survival rate. ${ }^{1,2}$ A maxillary sinus opacification with calcification on CT scan has a $55.6 \%$ probability of being fungal rhinosinusitis. ${ }^{3,4}$ A calcified thyroid nodule on CT scan suggests thyroid cancer in $87.5 \%$ of cases. ${ }^{5}$ An incidental finding of enlarged parathyroid or parathyroid adenoma during thyroidectomy is $1.2 \% .^{6}$ These findings all require surgery, but it is very rare that they are found to occur simultaneously in one patient.

This case report describes a rare combination of early tongue cancer, incidental calcification of maxillary sinus and calcification of thyroid nodules, and primary hyperparathyroidism in a 70-year-old.

Corresponding author: Precious Eunice R. Grullo MD, MPH

Department of Otorhinolaryngology

2nd Floor, Ward 10

Philippine General Hospital

University of the Philippines Manila

Taft Avenue, Ermita, Manila 1000 Philippines

Telephone: +632 5548400 local 2151 or 2152

Email: prgrullo@up.edu.ph

\section{Case Report and Discussion}

The patient presented with a one year enlarging $2 \mathrm{~cm} \mathrm{x}$ $1 \mathrm{~cm}$ right lateral ulcerated tongue mass. She had controlled diabetes, an ill-fitting denture, but no history of smoking or alcohol intake. The family had no history of cancer. Contrast CT scan of the oral cavity showed a $1.6 \times 1.2 \times 1.4 \mathrm{~cm}$ ovoid homogenously enhancing lesion at the right lateral tongue, without invasion of the intrinsic tongue muscles (Figure 1). The usual treatment course is a biopsy, which is both diagnostic and therapeutic. She opted for an outright excision biopsy under general anesthesia.

Neck CT scan did not reveal any sign of neck node disease; however, incidental findings of soft tissue density with calcifications at the right maxillary sinus (Figure 2), and $1.4 \times 1.1 \times 1.5 \mathrm{~cm}$ hypodense, heterogeneous nodule with peripheral calcifications in the right thyroid lobe (Figure 3) and $0.8 \mathrm{~cm}$ coarse calcification at the isthmus. Chest x-ray and liver ultrasound were normal. The initial impression was a possible tongue cancer T1N0M0, fungal maxillary rhinosinusitis in a diabetic patient and thyroid cancer. A retropharyngeal left carotid artery displacement was also noted, about which the anesthesiologist was informed.

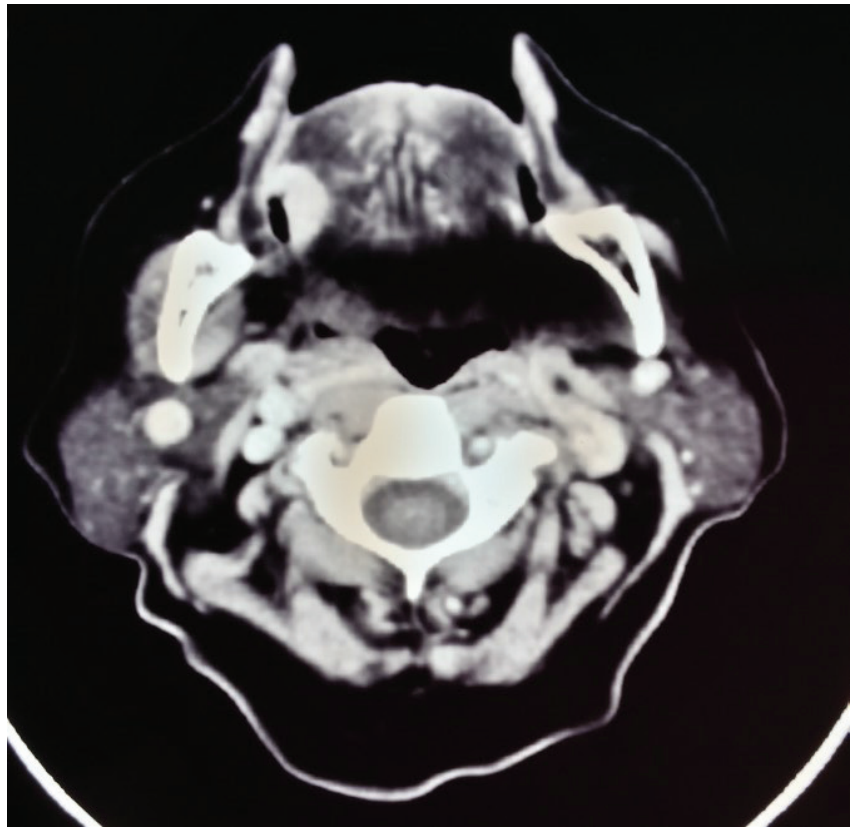

Figure 1. 1.6x1.2x1.4 cm ovoid homogenously enhancing lesion at the right lateral tongue. 


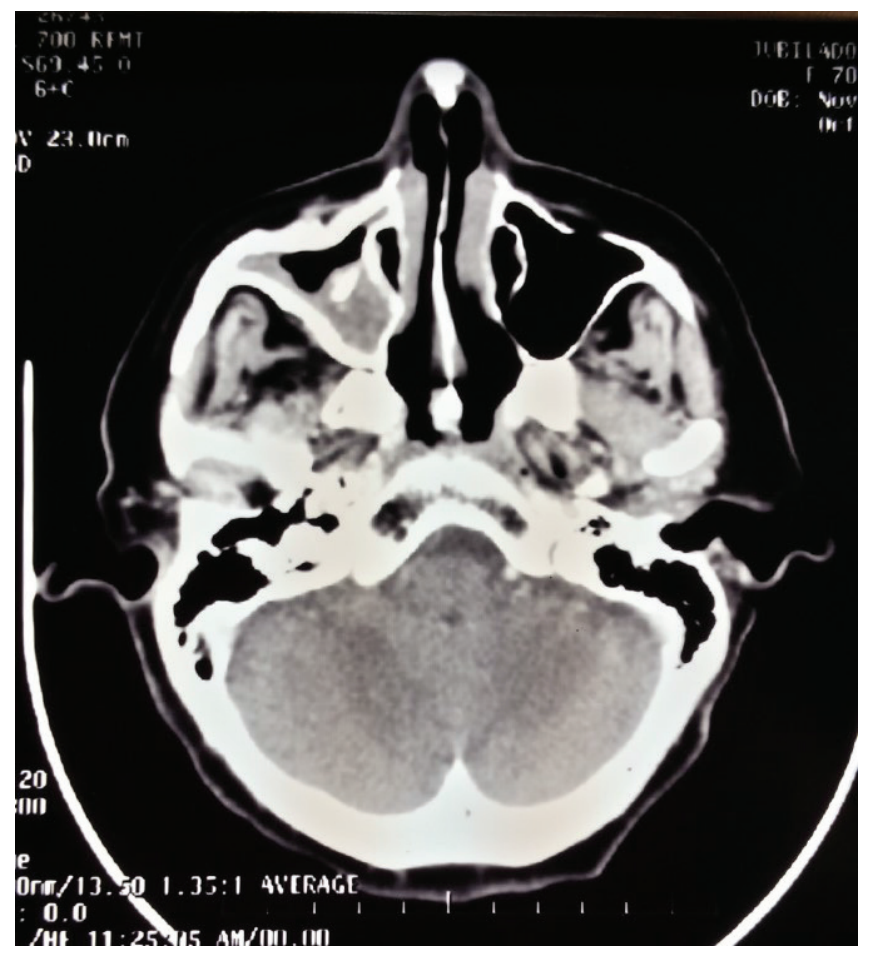

Figure 2. Right maxillary sinus opacification with radiographic heterogeneity found in maxillary sinus fungal ball due to Aspergillus.

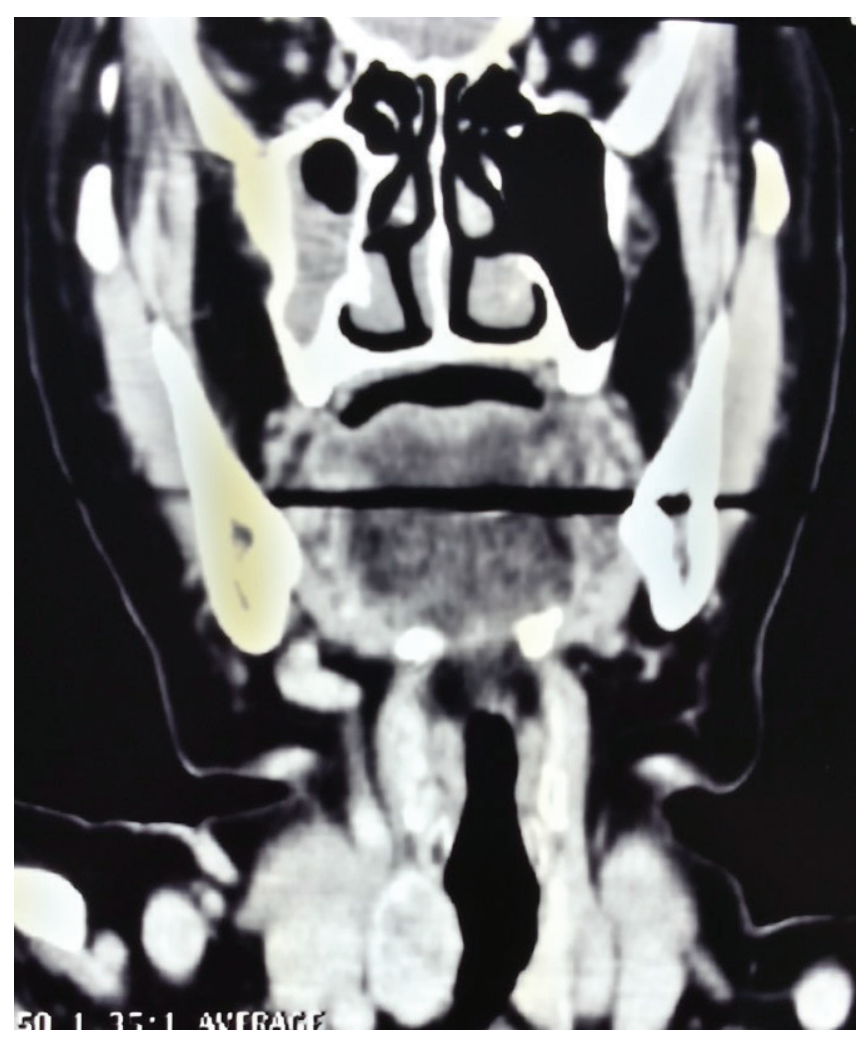

Figure 3. $1.4 \times 1.1 \times 1.5 \mathrm{~cm}$ hypodense, heterogeneous nodule with peripheral calcifications in the right thyroid lobe.
The initial procedure consisted of total thyroidectomy, excision of tongue mass with $1 \mathrm{~cm}$ margins, and endoscopic sinus surgery. Excision of the right lateral tongue mass with $1 \mathrm{~cm}$ margin showed uninvolved intrinsic and extrinsic muscles of the tongue. Primary closure was done. Endoscopic uncinectomy and widening of the maxillary ostium allowed evacuation of soil like material in the right maxillary sinus. Total thyroidectomy showed multiple nodules in the right lobe and isthmus, with an incidental finding of a distinct $0.5 \mathrm{~cm}$ inferior parathyroid gland, which was preserved with the rest of the parathyroid glands and recurrent laryngeal nerves. This intraoperative incidental finding of an enlarged parathyroid interestingly raised a question: what if this is a parathyroid adenoma causing ectopic calcifications? True enough, post-operative ionized calcium testing revealed hypercalcemia (1.65 $\mathrm{mmol} / \mathrm{l})$ instead of a possible transient hypocalcemia, and the incidental finding was confirmed with elevated intact parathyroid hormone (iPTH) at $72.75 \mathrm{pg} / \mathrm{ml}$ and Sestamibi scan showing a Sestamibi-avid focus at the midline anterior inferior cervical region. Final histopathology report revealed $2.0 \times 1.5 \times 0.5 \mathrm{~cm}$ well-differentiated squamous cell carcinoma tongue mass (Figure 4) with negative surgical margins, Aspergillus fungal balls in maxillary content (Figure 5), and multiple 1.0-2.0 cm adenomatous thyroid colloid nodules (Figure 6). These findings led to a decision to perform second stage surgery.

One month after the initial surgery, second stage surgery involving parathyroidectomy of a distinct $0.5 \times 1 \mathrm{~cm}$ mass, right elective neck dissection of level I-III and right partial glossectomy of $1 \mathrm{~cm}$ margins was performed. Surgery took 2 hours. Postoperative ionized calcium was normalized

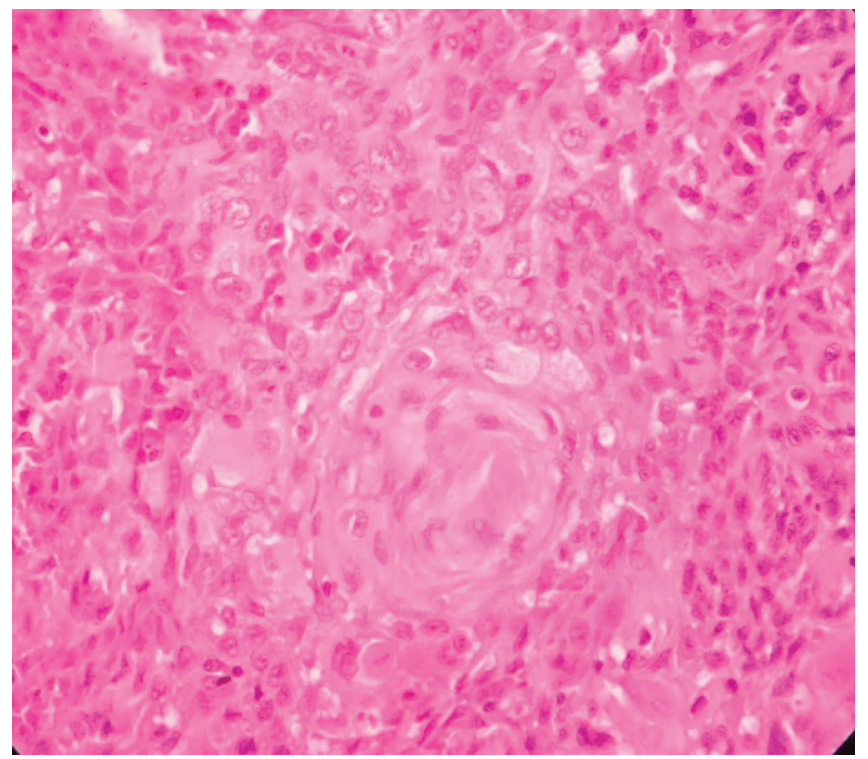

Figure 4. High-magnification photomicrograph (hematoxylin and eosin; $\times 400$ ) of tongue biopsy showing keratin pearl. 


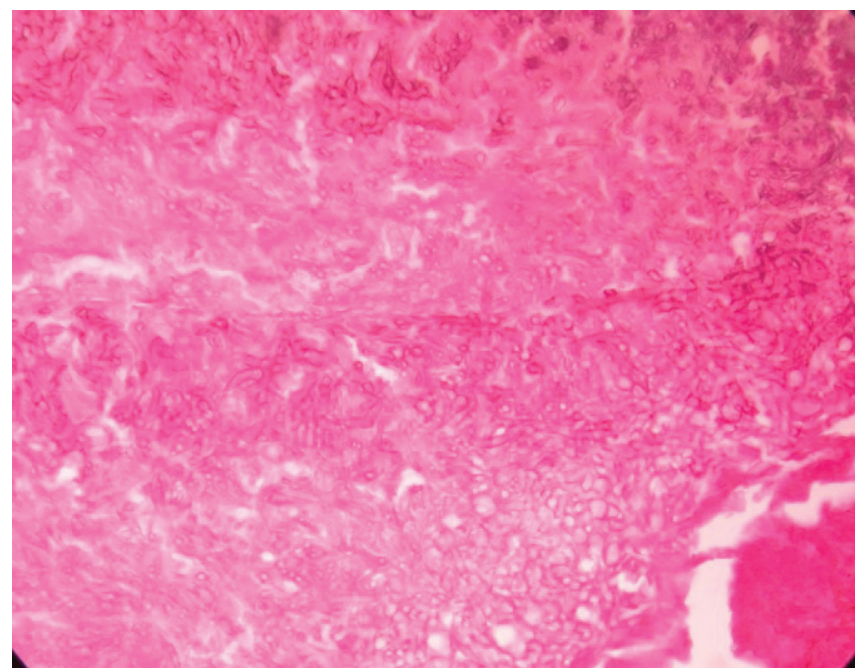

Figure 5. Low-magnification photomicrograph (hematoxylin and eosin; $\times 40$ ) of maxillary sinus contents showing dichotomously branching hyphae at acute angles characteristic of Aspergillus.

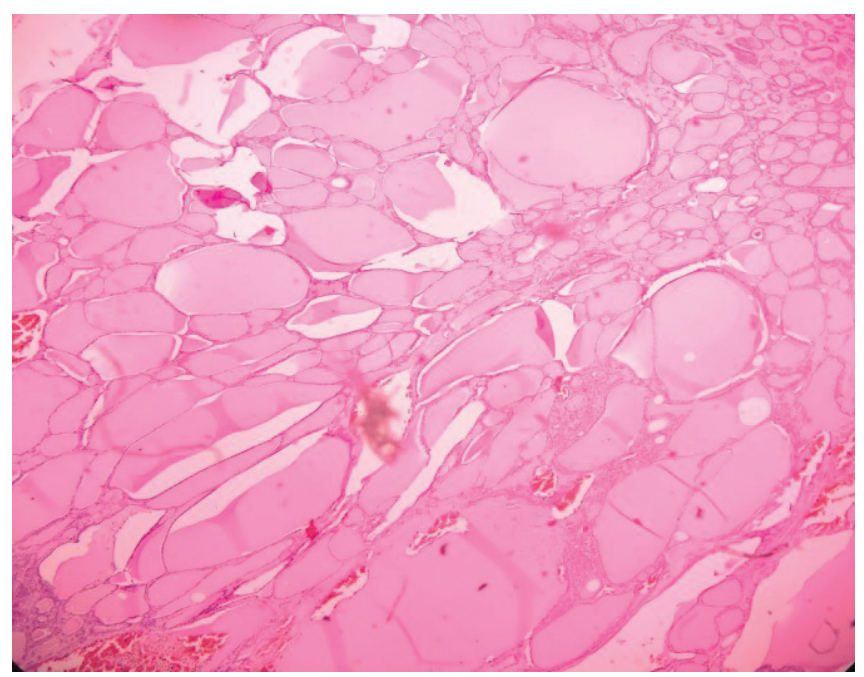

Figure 6. Low-magnification photomicrograph (hematoxylin and eosin; $\times 40$ ) of a section from the right thyroid lobe showing colloid filled follicles.

at $9.81 \mathrm{mg} / \mathrm{dl}$. Histopathology showed $0.8 \mathrm{~cm}$ parathyroid tissue, and negative for cancer right cervical level I-III lymph tissue and submandibular gland and $0.8 \mathrm{~cm}$ tongue margins. The patient had no complications.

Six months post-surgery, physical findings and CT scan did not show any signs of recurrence, while intact PTH is of normal levels. There is no swallowing difficulty, and minimal difficulty in articulation.

In retrospect, an intraoperative calcium testing for incidental findings of enlarged parathyroid, or an outright removal of the solitary enlarged parathyroid should have been done. ${ }^{6,7}$ Metastatatic calcification in the thyroid gland attributed to primary hyperparathyroidism has been suggested in literature. ${ }^{8}$ However, in this case, due to the known high rates of malignancy in calcified thyroid nodules, total thyroidectomy had to be done.

This unique case presented with a combination of early tongue cancer T1N0M0, maxillary fungal rhinosinusitis, parathyroid adenoma and multinodular adenomatous goiter. While our threshold to proceed with treatment modalities, such as surgery, is guided by weighing probability of disease, risk of complications and degree of benefits, we occasionally find ourselves "individualizing" more than usual if a patient presents with multiple incidental findings. A second stage surgery was done to maximize treatment: parathyroidectomy, elective neck dissection level I-III and hemiglossectomy of additional $1 \mathrm{~cm}$ margin.

In managing multiple diseases in a single patient, multiple causes that can produce the observed findings, and not just the simplest or most straightforward ones, should be considered. Multiple ectopic calcifications in the head and neck may suggest multiple unrelated diseases or an undiagnosed hypercalcemia. Serum calcium levels should routinely be determined in diseases presenting with incidental findings of multiple site calcification. Individualized care combined with evidence based medicine provides best treatment options for the patient as well as the health care provider.

\section{Author Disclosure}

There are no competing interests and financial funding that need to be disclosed.

\section{References}

1. Peng KA, Chu AC, Lai C, et al. Is there a role for neck dissection in T1 oral tongue squamous cell carcinoma? The UCLA experience. Am J Otolaryngolol. 2014; 35(6):741-6.

2. Feng Z, Li JN, Li CZ, Guo CB. Elective neck dissection versus observation in the management of early tongue carcinoma with clinically node-negative neck: a retrospective study of 229 cases. J Craniomaxillofac Surg. 2014; 42(6):806-10.

3. Yoon JH, Na DG, Byun HS, Koh YH, Chung SK, Dong HJ. Calcification in chronic maxillary sinusitis: comparison of CT findings with histopathologic results. Am J Neuroradiol. 1999; 20(4):571-4.

4. Chakrabarti A, Denning DW, Ferguson BJ, et al. Fungal rhinosinusitis : a categorization and definitional schema addressing current controversies. Laryngoscope. 2009; 119(9):1809-18. doi:10.1002/lary.20520.

5. Zhu D, Chen W, Xiang J, Han Z. Diagnostic value of CT artifacts for solitary coarse calcifications in thyroid nodules. Int J Clin Exp Med. 2015; 8(4):5800-5.

6. Shroff P, McGrath GA, Pezzi CM. Incidentalomas of the parathyroid gland: multiple presentations, variable function and review of the literature. Endocr Pract. 2005; 11(6):363-9. Available from doi:10.4158/ EP.11.6.363.

7. Carnaille BM, Pattou FN, Oudar C. Lecomente-Houcke MC, Rocha JE, Proye CA. Parathyroid incidentalomas in normocalcemic patients during thyroid surgery. World J Surg. 1996; 20(7):830-4.

8. Amico S, Lucas P, Diebold MD, Liehn JC, Petit J, Valeyre J. Metastatic calcification in the thyroid gland demonstrated on bone scan in a patient with primary hyperparathyroidism. J Nucl Med. 1986; 27(3):373-6. 